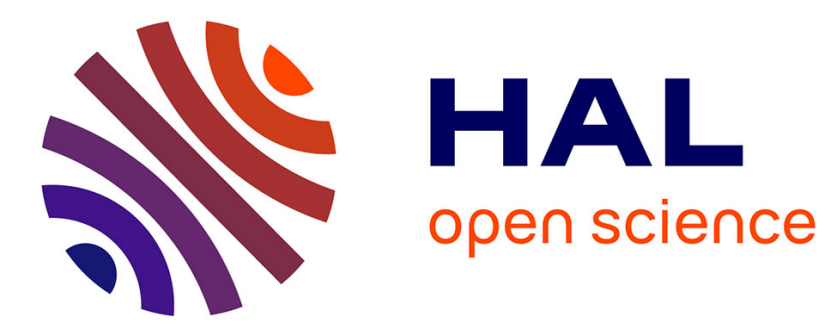

\title{
Gadolinium nanoparticles and contrast agent as radiation sensitizers
}

F. Taupin, M. Flaender, R. Delorme, T. Brochard, J.F. Mayol, J. Arnaud, P. Perriat, Lucie Sancey, F. Lux, R.F. Barth, et al.

\section{- To cite this version:}

F. Taupin, M. Flaender, R. Delorme, T. Brochard, J.F. Mayol, et al.. Gadolinium nanoparticles and contrast agent as radiation sensitizers. Physics in Medicine and Biology, 2015, 60 (11), pp.4449-4464. 10.1088/0031-9155/60/11/4449 。 in2p3-01157446

HAL Id: in2p3-01157446

https://hal.in2p3.fr/in2p3-01157446

Submitted on 9 May 2019

HAL is a multi-disciplinary open access archive for the deposit and dissemination of scientific research documents, whether they are published or not. The documents may come from teaching and research institutions in France or abroad, or from public or private research centers.
L'archive ouverte pluridisciplinaire HAL, est destinée au dépôt et à la diffusion de documents scientifiques de niveau recherche, publiés ou non, émanant des établissements d'enseignement et de recherche français ou étrangers, des laboratoires publics ou privés. 


\section{Gadolinium nanoparticles and contrast agent as radiation sensitizers}

Florence Taupin ${ }^{*, 1,2,3,4,5}$, Mélanie Flaender ${ }^{*, 1,4}$, Rachel Delorme ${ }^{5}$, Thierry Brochard ${ }^{4}$, JeanFrançois Mayol ${ }^{7}$, Rolf F. Barth ${ }^{8}$, Marie Carrière ${ }^{2,3}$, Jean-Luc Ravanat ${ }^{2,3,4}$ and Hélène Elleaume $^{1,4,6}$.

* Both authors equally contributed to the manuscript.

${ }^{1}$ INSERM U836 Équipe 6, Grenoble Institut des Neurosciences, Grenoble, France.

${ }^{2}$ Univ. Grenoble Alpes, INAC-SCIB, LAN, F-38000 Grenoble, France

${ }^{3}$ CEA, INAC-SCIB, F-38000 Grenoble, France

${ }^{4}$ European Synchrotron Radiation Facility, Medical Beamline ID17, Grenoble, France.

${ }^{5}$ LIST, Laboratoire d'Intégration de Systèmes et des Technologies, CEA Saclay, France.

${ }^{6}$ Université Joseph Fourier; Centre Hospitalier Universitaire, Grenoble, France.

${ }^{7}$ Institut de Recherche Biomédicale des Armées, La Tronche, France.

${ }^{8}$ Department of Pathology, the Ohio State University, Columbus, $\mathrm{OH} 43210$, U.S.A.

\section{Running title: GdNPs as radiation sensitizers}

\section{Corresponding author:}

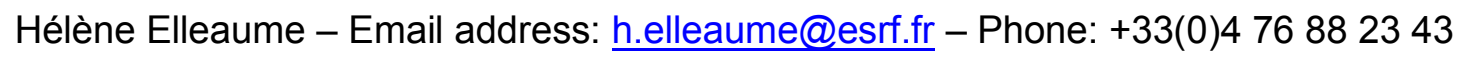

Mailing address: ESRF-ID17; 6, rue Jules Horowitz; 38000 Grenoble; FRANCE 
Conflict of Interest: none

Acknowledgments: This work was performed within the framework of the "Labex Primes" (ANR-11-LABX-0063) of Lyon University, within the program "Investissements d'Avenir" (ANR11-IDEX-0007) and ANR project "Raphaelo" ANR-2010-BLAN-1532-02 operated by the French National Research Agency (ANR). We warmly thank Olivier Tillement, Lucie Sancey, Francois Lux, Gustavo B. Alcantara and Pascal Perriat (Université de Lyon, INSA, Lyon, France) for the furniture and characterization of the Gd nanoparticles. This manuscript is dedicated to the memory of Pascal Perriat who passed away recently. 


\section{ABSTRACT}

The goal of the present study was to evaluate and compare the radiosensitizing properties of gadolinium nanoparticles (NPs) with the gadolinium contrast agent (GdCA) Magnevist ${ }^{\circledR}$ and to better understand the mechanisms by which they act as radiation sensitizers. This was determined following either low energy synchrotron irradiation or high energy gamma irradiation of F98 rat glioma cells exposed to ultrasmall gadolinium NPs (GdNPs, $3 \mathrm{~nm}$ ) or GdCA. Clonogenic assays were used to quantify cell survival after irradiation in the presence of $\mathrm{Gd}$ using monochromatic X-rays with energies in the $25 \mathrm{keV}-80 \mathrm{keV}$ range from a synchrotron and $1.25 \mathrm{MeV}$ gamma photons from a cobalt-60 source. Radiosensitization was demonstrated with both of these agents in combination with X-irradiation. At the same concentration $(2.1 \mathrm{mg} / \mathrm{mL})$, GdNPS showed a more important effect than GdCA. The maximum sensitization-enhancement ratio at $4 \mathrm{~Gy}\left(\mathrm{SER}_{4 \mathrm{~Gy}}\right)$ was observed at $65 \mathrm{keV}$ irradiation energy, both for the nanoparticles and the contrast agent: SER $\mathrm{SGy}_{4}=2.47 \pm 0.30$ and $1.41 \pm 0.15$, for GdNPs and GdCA, respectively. At high energy (1.25 MeV), radiosensitization was observed with GdNPs only: SER $4 \mathrm{~Gy}=1.59 \pm 0.13$ and $1.02 \pm 0.13$, for GdNPs and GdCA, respectively. The radiation dose enhancements were highly "energy dependent" for both agents, which allowed us to better understand the fundamental mechanisms that were involved. Photoactivation appeared to be the primary mechanism by which $\mathrm{Gd}$ contrast agents can function as radiosensitizers. Other mechanisms, such as alterations in the cell cycle and proliferation may explain the enhanced radiosensitizing properties of GdNPs.

Keywords: Gadolinium, nanoparticles, contrast agent, photoactivation, radiosensitization, Xrays 


\section{BACKGROUND}

High grade gliomas are the most common primary malignant brain tumor in adults. They are almost invariably fatal with the current standard therapy consisting of surgery, radiotherapy and the concomitant administration of temozolomide (TMZ) followed by repetitive cycles of the latter treatment [1, 2]. Although the increase in overall median survival was only 2.5 months (14.6 vs 12.1 months), approximately $25 \%$ of patients were still alive at 2 years compared to less than $10 \%$ for those that did not received TMZ. The poor prognosis of patients with high grade gliomas highlights the necessity of evaluating new therapeutic approaches. Nanoparticles (NPs) are being evaluated as theranostics for radiation therapy. Hainfeld et al. [3] have shown that gold nanoparticles (AuNPs) could enhance the efficacy of radiation therapy for the treatment of the EMT-6 murine mammary carcinoma, and more recently a murine brain tumor model [4]. This therapeutic approach, initially proposed by Norman et al. [5] was based on the principle that the physical dose delivered locally to a tumor could be enhanced by the photon interactions that would occur within a tumor that had been loaded with high-Z atoms $[6,7]$. The first studies were performed using molecular contrast agents (CA) and low energy $\mathrm{X}$ rays $(<100 \mathrm{keV})$, where the photoelectric effect's cross-section was maximal compared to water. In the present study we have used gadolinium, which has been widely used clinically as a contrast agent (CA) but it also could be used as a photoactivator [8, 9]. When irradiated with X-rays, Gd generates electrons that have a kinetic energy equal to the difference between the incident photons' energy and the electron binding energies. K-edge photoelectrons (15 $\mathrm{keV}$ ) created by photoionization of $\mathrm{Gd}$ atoms by $65 \mathrm{keV}$ photons have a mean path length in water of $\sim 8 \mu \mathrm{m}$, which is similar to the diameter of a cell. In this case, extracellular Gd atoms could have a direct effect on cell survival if a sufficient quantity of Gd atoms is localized in proximity or within the cell. Furthermore, following a K-edge photoelectric event, K-shell vacancies are created and subsequently filled with higher orbital electrons. The electronic reorganization of the $\mathrm{Gd}$ atoms yields a cascade of either fluorescence X-rays or Auger electrons that have very low energies, which are deposited very close to their site of production [10, 11]. 
If the high-Z atoms remain external to the cell nucleus, Auger electrons would not reach the nucleus but could damage other cellular targets such as the cell membrane and mitochondria.

Using high energies, such as those produced by a linear accelerator (LINAC), the photoelectric effect would no longer predominate and much lower dose enhancement factors (DEFs) would be expected. Monte Carlo simulations have been developed to evaluate the physical dose-enhancement induced by the presence of the high $Z$ elements, based on their homogeneous distribution within a cell [7, 12, 13]. For example, Robar et al. [14] have reported on the DEFs simulated in a numeric head phantom for different Gd concentrations in the tumor as a function of the radiation energy. The calculated DEFs were 1.2 and 5.3 for a $2 \mathrm{MeV}$ or 60 $\mathrm{keV}$ X-ray beam, respectively, with $30 \mathrm{mg} / \mathrm{mL}$ of $\mathrm{Gd}$ in the tumor [14]. The calculated and experimental dose-enhancement factors (DEF) were found to be in good agreement at a macroscopic scale in other studies $[15,16]$.

Although most studies refer to larger DEFs in the $\mathrm{keV}$ range, as predicted theoretically, radiosensitization at $\mathrm{MeV}$ photon energies also has been reported with NPs [17, 18]. Jain et al. $[19,20]$ have observed dose enhancement greater than MC simulations after irradiation of MDA-MB-231 breast cancer cells at MeV photon energies with $1.9 \mathrm{~nm}$ AuNPs. However, contradictory results also have been reported depending on the energy range considered [2125]. Recently, Mowat et al. [26, 27] have utilized ultrasmall GdNPs as radiosensitizers for tumor cells. The NPs consisted of a core of gadolinium oxide surrounded by a shell of polysiloxane and were functionalized by diethylenetriaminepentaacetic acid (DTPA). These also have been used in vivo for the treatment of $9 \mathrm{~L}$ gliosarcoma bearing rats in combination with $\mathrm{X}$-ray microbeams $(E<150 \mathrm{keV})$ [28]. The median survival time was extended to 90 days compared to 47 days for irradiation alone. The underlying mechanisms by which radiosensitization increased in presence of the NPs following irradiation are still unclear. Monte Carlo simulations have shown that the assembly of heavy atoms within the NPs strongly modified the dose patterns at the nanoscale. Radiation doses were found to be higher within a few nanometers surrounding the NPs compared to those measured in water when using either high energy $(\mathrm{MeV}) \mathrm{X}$-rays or those in the photoelectric domain. However, simulations predicted that the 
enhancement was much greater using kilovoltage energies compared to high energy $\mathrm{X}$-rays $[21,23,24,29]$.

Since the physical DEF is strongly energy dependent $[10,15,21,30-34]$, monochromatic radiation produced by a synchrotron source provides a unique tool for evaluating the mechanisms by which radiosensitization occurs and can be used to differentiate between physical and biological contributors to dose enhancement. The aim of the present study was to evaluate the in vitro radiosensitizating effects produced by ultrasmall GdNPs compared to those produced by GdCA, homogeneously distributed around the cells during irradiation and for different energies. In order to determine the relative importance of physical and biological contributions to the overall observed radiosensitizing effects on rat glioma F98 cells, clonogenic assays were performed using different incubation and irradiation conditions with either monochromatic X-rays from a synchrotron source ( 7 energies from $25 \mathrm{keV}$ to $85 \mathrm{keV}$ ) or a cobalt-60 source (1.25 MeV).

\section{METHODS}

\section{Gadolinium compounds}

GdNPs ( $3 \mathrm{~nm}$ in diameter) were provided by Nano-H (Lyon, France). A detailed description of their synthesis and properties has been reported elsewhere [35]. Briefly summarized, they were composed of $8.5 \pm 0.1 \mathrm{kDa}$ particles containing 10 molecules of $1,4,7,10$ tetraazacyclododecane-1,4,7,10-tetraacetic acid (DOTA), $7 \mathrm{Gd}$ and $27 \mathrm{Si}$ atoms per particle. The NPs were labeled with fluorescein isothiocyanate (FITC). The Gd contrast agent (GdCA) Magnevist ${ }^{\circledR}$ ) (14) chemical formula $\mathrm{C}_{28} \mathrm{H}_{54} \mathrm{GdN}_{5} \mathrm{O}_{20}$, molecular weight of $938 \mathrm{Da}$, was obtained from Bayer Schering Pharma, Berlin, Germany.

\section{F98 cells}

F98 glioma cells were purchased from the American Type Culture Collection, Manassas, VA (ATCC, \# CRL-2397) and they have been described in detail by Barth and Kaur (36). These cells are known to have a highly invasive pattern of growth and being weakly immunogenic (36). 


\section{Determination of gadolinium nanoparticles uptake}

Gd uptake was determined by means of ICP-MS using a Thermo X serie II, spectrometer (Thermo Electron, Bremen, Germany), which was equipped with an impact bead spray chamber and a standard nebulizer $(1 \mathrm{~mL} / \mathrm{min})$. Three different treatment times were investigated, $30 \mathrm{~min}, 2 \mathrm{~h}$ and $5 \mathrm{~h}$, following incubation with GdNPs at a concentration of $2.1 \mathrm{mg}$ $\mathrm{Gd} / \mathrm{mL}$. For Gd determinations, the cells were washed twice in PBS, trypsinized (Trypsine EDTA $0.05 \%$ - Invitrogen), suspended in $1 \mathrm{~mL}$ of PBS, and then counted. Nitric acid was then added to the cell suspensions (final concentration 1\%) and Gd concentrations were determined using an external calibration curve. Two stable $\mathrm{Gd}$ isotopes $\left({ }^{155} \mathrm{Gd}\right.$ and $\left.{ }^{157} \mathrm{Gd}\right)$ were measured and rhodium $\left({ }^{103} \mathrm{Rh}\right)$ was used as an internal standard. Determinations were carried out in triplicate.

\section{Cell cycle distribution}

The cell cycle distribution of F98 cells incubated with GdNPs $(2.1 \mathrm{mg} / \mathrm{mL}, 5 \mathrm{~h})$ was determined from DNA histograms measured by flow cytometry. After incubation, the culture medium was decanted and the cells were trypsinized, washed twice with PBS and fixed with a $2 \%$ formalin solution. Cell membranes were permeabilized with $0.2 \%$ Triton $\mathrm{X}-100$ in PBS. DNA was determined by fluorescent staining with DAPI $(10 \mu \mathrm{g} / \mathrm{mL})$ with a flow cytometer (LSR II, BD Bioscience, Franklin Lakes, USA). Cell cycle distribution was determined either immediately or $24 \mathrm{~h}$ after incubation with GdNPs and compared to untreated control cells. Cell cycle analysis was performed after doublet exclusion using FlowJo software (Tree Star, INC. Ashland, OR) and Watson DNA peak deconvolution.

\section{Cell irradiations}

Three treatment conditions were evaluated: 1 ) untreated control cells; 2) cells incubated for $5 \mathrm{~h}$ with $2.1 \mathrm{mg} / \mathrm{mL} \mathrm{GdNPs}$; and 3) cells irradiated in the presence of $2.1 \mathrm{mg} / \mathrm{mL} \mathrm{GdCA}$ (Magnevist ${ }^{\circledR}$ ). Before irradiation, cells were trypsinized, washed and re-suspended in $200 \mu \mathrm{L}$ of DMEM complete media (with or without $\mathrm{Gd}$ ) and irradiated in Eppendorf tubes.

Low energy monoenergetic X-rays (from 25 to $80 \mathrm{keV}$ ) were produced from a synchrotron source at the European Synchrotron Radiation Facilty (ESRF - biomedical ID17 beamline - 
$\Delta \mathrm{E} / \mathrm{E} \approx 0.1 \%$ ). The dosimetry was performed using an ionization chamber (PTW Semiflex ion chamber $31010-0.125 \mathrm{~cm}^{3}$ ). High energy irradiations were carried out using a cobalt-60 source, which emitted gamma photons with energies of 1.17 and $1.33 \mathrm{MeV}$ (1.25 MeV mean energy). For radiosensitization versus photon energy, cells were irradiated at a single $4 \mathrm{~Gy}$ dose with beam energy 31.0, 40.0, 49.5, 51.0, 65.0, $80.0 \mathrm{keV}$ and 1. $25 \mathrm{MeV}$. For doseresponse curves, samples were irradiated with $0,2,4$ or 6 Gy and with a beam energy of $51 \mathrm{keV}$ (just above the Gd K-edge).

\section{Clonogenic assays}

Clonogenic assays were used for determining the sensitizing enhancement produced by $\mathrm{Gd}$ in combination with X-irradiation. Following treatment, the cells were counted and diluted in the appropriate volume of DMEM. Three different cells concentrations were seeded in triplicate into Petri dishes (100 mm diameter) containing $8 \mathrm{~mL}$ of complete DMEM. The petri dishes were incubated at $37^{\circ} \mathrm{C}$ in an atmosphere containing $95 \%$ air and $5 \% \mathrm{CO}_{2}$ for 11 days. All experiments were repeated three times. Following staining with crystal violet, colonies of greater than 50 cells were enumerated. The surviving fractions (SF) were determined as the ratio of the number of colonies counted divided by the number of cells plated, normalized to un-irradiated controls.

\section{Cell survival and sensitization-enhancement ratio at $51 \mathrm{keV}$}

Radiation dose response curves obtained at $51 \mathrm{keV}$ were fitted by the linear quadratic (LQ) model: $S=e^{-\left(\alpha D+\beta D^{2}\right)}$ with, $\mathrm{D}(\mathrm{Gy})$ the radiation dose, $\mathrm{S}$ the normalized survival fraction and two parameters, $\alpha\left(G y^{-1}\right)$ and $\beta\left(G y^{-2}\right)$. The $\alpha$ parameter characterizes the first part of the slope of the cell survival curve and the effectiveness at low doses, while $\beta$ represents the contribution from cumulative damages, presumably due to the interaction of two or more lesions. The $\alpha / \beta$ ratio represents the dose at which the linear and quadratic terms contribute equally to the total effect. The sensitizing Enhancement Ratio (SER) was calculated as the ratio of the Survival fraction for control cells (computed with the corresponding $\alpha$ and $\beta$ parameters) to that of cells irradiated in combination with Gd. 


\section{Sensitization-enhancement ratio versus energy}

The sensitizing Enhancement Ratio versus energy (SER GGy $_{4}$ ) was defined as the ratio of the SF for control cells (4 Gy irradiation alone) to that of cells irradiated with $4 \mathrm{~Gy}$ with $\mathrm{Gd}$.

\section{Statistical analysis}

All experiments were performed 3 times with triplicate samples in each study and the final data represented the means from the three independent experiments. The statistical errors corresponded to their standard deviation (SD) and the error bars on graphs indicated 1 SD. Statistical differences between the experimental results were evaluated using Student's twotailed t-test, which was the most suitable method for the analysis of small samples $(n<30)$. Differences were considered significant at the level of $p \leq 0.05$.

\section{Computed Macroscopic Dose-Enhancement Factor (DEF)}

Monte Carlo simulations (MCNPX version v27e) were used to estimate the macroscopic physical dose enhancement produced by Gd during irradiation. The input geometry was defined by a cube $\left(1 \mathrm{~cm}^{3}\right.$, imbedded in air) containing either water or a solution of $\mathrm{Gd}$ mixed homogeneously in water at a concentration of $2.1 \mathrm{mg} \mathrm{Gd} / \mathrm{mL}$. The dose enhancement factor (DEF) was defined as the ratio between the doses deposited in the cube containing Gd to that deposited in a cube only containing water. DEFs were calculated for the same energies as those used for cell irradiations between $25 \mathrm{keV}$ to $1.25 \mathrm{MeV}$ and using $10^{8}$ incident photons per irradiation to obtain uncertainties $<5 \%$. A square source $(2 \times 2 \mathrm{~cm})$ was centered on the cube and placed at a distance of $4.5 \mathrm{~cm}$ in front of it.

\section{Computed Sensitization-enhancement Ratio}

The theoretical sensitization-enhancement ratio (SER) is calculated, assuming that radiosensitization in presence of $\mathrm{Gd}$ is uniquely induced by physical effects. The normalized survival fraction in presence of $\mathrm{Gd}\left(\mathrm{SF}_{\mathrm{Gd}}\right)$ is calculated using the parameters $\alpha$ and $\beta$ (obtained from the $\left.\mathrm{SF}_{\text {control }}\right)$ and the computed dose-enhancement factor (DEF), as follows:

$$
\begin{gathered}
S E R=S F_{\text {control }} / S F_{G d} \\
S F_{\text {control }}=\exp \left(-\alpha D-\beta D^{2}\right) \\
\left.S F_{G d}=\exp \left(-\alpha D \times D E F-\beta(D \times D E F)^{2}\right)\right)
\end{gathered}
$$




$$
\begin{gathered}
S E R=S F_{\text {control }} / S F_{G d} \\
S E R=\exp \left(\alpha D \times(D E F-1)+\beta D^{2}\left(D E F^{2}-1\right)\right)
\end{gathered}
$$

With:

- $\mathrm{SF}_{\mathrm{Gd}}$ and $\mathrm{SF}_{\text {control, }}$ the normalized survival fractions measured experimentally with and without $\mathrm{Gd}$, respectively.

- $\alpha$ and $\beta$ are the control cells radiosensitivity parameters (in absence of radio-sensitizer) extracted from the $S F_{\text {control }}$ curve using the LQ model.

- $\quad$ The DEF is calculated using Monte Carlo simulations, as previously described.

\section{RESULTS}

\section{Radiosensitization versus radiation dose, measured above the Gadolinium K-edge.}

In order to assess the radiosensitization potential of GdNPs, F98 glioma cells were incubated for $5 \mathrm{~h}$ with $2.1 \mathrm{mg} / \mathrm{mL}$ of GdNPs, then irradiated with a monochromatic photon beam at 51 keV. For comparison, F98 cells were also irradiated with $0,2.1,5.0$ or $10.0 \mathrm{mg} / \mathrm{mL}$ of $\mathrm{GdCA}$ in the culture medium. At $0 \mathrm{~Gy}$, SF of F98 cells incubated with GdNPs was $0.96 \pm 0.11$. The normalized survival values with the contrast agent were $1.00 \pm 0.15,1.01 \pm 0.15,1.08 \pm 0.17$ and $1.07 \pm 0.14$, for the 4 increasing GdCA concentrations respectively, indicating that both agents were non-toxic in these experimental conditions. The survival curves versus $\mathrm{X}$-ray dose are shown in Figure 1. The cell radiosensitivity parameters $\alpha$ and $\beta$ are shown in Figure 2 for all control and treated cells conditions. Gadolinium induced cells radiosensitization in all cases. Both GdNPs and GdCA induced a large increase of the linear parameter $\alpha$, and a decrease of $\beta$. For GdCA, the increase of $\alpha$ depends on the Gd concentration (Figure 2). The sensitizationenhancement ratios in presence of $\mathrm{Gd}$ compounds versus the radiation dose are shown in Figure 3. The sensitization-enhancement ratios reach a plateau after $5 \mathrm{~Gy}$, when cells were irradiated in presence of GdNPs. On the contrary, in presence of GdCA, the SERs increase, both with $\mathrm{Gd}$ concentration and X-ray dose. 


\section{Radiosensitization versus photon energy measured at 4 Gy}

Figure 4 summarizes the SER 4 Gy measured for GdNPs and GdCA in comparison with the theoretical SER 4 Gy. The experimental sensitization factors for GdCA, were in good agreement with theoretical SER ${ }_{4 G y}$ at all energies. As expected, the greatest enhancement was obtained at $65 \mathrm{keV}$ and no radiosensitization was observed when irradiation was performed at high energy (1.25 MeV) (Figure 4). Cells irradiated in presence of GdNPs had significantly higher SER $_{4 G y}$ values compared to GdCA at all energies. As for GdCA, the highest sensitization enhancements were obtained when the cells were irradiated at $65 \mathrm{keV}$. A significant increase of the SER 4 Gy was observed above and below the Gd K-edge (50.25 keV). GdNPs also led to a radiosensitizing effect for high-energy irradiations.

\section{GdNPs quantification}

The kinetics for the uptake of GdNPs by F98 cells was determined by means of ICP-MS. The amount of $\mathrm{Gd}$ increased and reached a plateau of up to $0.60 \pm 0.06 \mathrm{pg} \mathrm{Gd} /$ cell after $5 \mathrm{~h}$ of incubation at $37^{\circ} \mathrm{C}$ with GdNPs at a concentration of $2.1 \mathrm{mg} / \mathrm{mL}$ (Figure 5).

\section{Cell cycle distribution}

Figure 6 depicts the proportions of F98 cells in different phases of the cell cycle for control cells and those incubated for $5 \mathrm{~h}$ with $2.1 \mathrm{mg} / \mathrm{mL}$ GdNPs. Immediately after incubation, no significant differences were observed between the two conditions $(p>0.5)$, for all phases. Twenty-four hours after termination of the incubation with GdNPs, a significant cellular accumulation was measured in $G 2 / M$ phase $(p<0.05)$.

\section{Discussion}

The important finding in the present study was that differences were observed between the radiosensitizing effects produced by Gd in the form of ultrasmall NPs and those produced by GdCA. Radiosensitization was strongly energy dependent for both chemical forms of Gd. Irradiation of F98 cells in the presence of GdNPs led to a significantly greater enhancement of radiosensitization than that produced by GdCA for the same concentration. The experimental $\mathrm{SER}_{4 \mathrm{~Gy}}$ was energy dependent and reached a maximum at $65 \mathrm{keV}$ (energy of theoretical 
maximum SER) of $2.47 \pm 0.30$, compared to $1.41 \pm 0.15$ for GdCA. In addition, GdNPs led to a significant increase in the SER 4 Gy for irradiations carried out above the Gd K-edge compared to that below the K-edge. This indicated that the photoelectric effect played a major role in the observed radiosensitivity enhancement. However, the SER4Gy also was found to be significantly greater than 1 for high-energy X-irradiation in presence of GdNPs, although theoretically, only minimal dose enhancement was expected at this energy (Figure 4). There are two possible hypothesis to explain the observed radiosensitization effect with GdNPs. Firstly, taking into account the structure of the NPs, the secondary electrons produced in the NPs deposit their energy in the immediate vicinity of the NPs and create very hot points of doses which can impair the cell structures, as determined by MC simulations (Delorme R. unpublished data). Secondly, biological mechanisms that make cells more sensitive to radiation also could be involved in the radiosensitization observed in the presence of GdNPs and this would explain the large SER values observed with high energy X-rays. Additional experiments have been performed to measure perturbations in cellular metabolism following exposure to GdNPs. Both cell cycle regulation and cell proliferation were affected by incubation with GdNPs. Proliferation temporarily was slowed down for up to 4 days after incubation (data not shown) and an accumulation of cells in G2/M phase was observed at $24 \mathrm{~h}$ after incubation (Figure 5). Other investigators have reported similar results that were cell line and NP type dependent. Coulter et al. [19] reported that MDA-MB-231 cells exhibited proliferation arrest and a sub-G1 accumulation after an exposure to $12 \mu \mathrm{M}$ of $1.9 \mathrm{~nm}$ AuNPs, whereas L132 cells were not affected after a similar exposure.

A good agreement was obtained between the experimental data and the calculated DEFs versus the photon energy (both low and high energies), for the contrast agent GdCA. This suggests that the physical dose enhancement induced by photoelectric effects on $\mathrm{Gd}$ atoms is the predominant mechanism that produced cell death. As predicted theoretically by $\mathrm{MC}$ simulations (Delorme et al. unpublished data) [21], no sensitization enhancement was observed following irradiation with $1.25 \mathrm{MeV}$ photons from a cobalt 60 source. The 
radiosensitization effect was directly proportional to the concentration of the high $Z$ atoms contained in the medium. Regarding the survival curves, the linear $\alpha$ component increased linearly $\left(R^{2}>0.95\right)$ with $\mathrm{GdCA}$ concentration (Figure 2$)$, which indicates that the main effect is an increase in the number of directly lethal events due to the presence of $\mathrm{Gd}$. The $\beta$ value was not significantly changed, indicating an intact repair of sub lethal damages [36].

In presence of nanoparticles, a marked increase of the linear a component was obtained (factor 150 relative to controls) and the quadratic term $\beta$ becomes negligible (Figure 2). Similar results were obtained with other cells lines and GdNPs [37]. This might be explained by cell cycle perturbations that occur in presence of GdNPs. Further investigations are warranted to support this hypothesis.

Differences of the sensitization-enhancement ratio between GdNPs and GdCA were also observed versus the X-ray dose as shown in Figure 3. For cells irradiated in presence of nanoparticles, a saturation is observed above 4 Gy (SER $\sim 2$ at $51 \mathrm{keV}$ ). On the contrary with Gd contrast agent, the sensitization-enhancement factors continue to increase, both with the radiation dose and the $\mathrm{Gd}$ concentration (SER 4 at 6 Gy in presence of $10 \mathrm{mg} / \mathrm{mL}$ of $\mathrm{GdCA}$ ). These results suggest that it could be favorable to choose radiation doses $\sim 4$ Gy when using GdNPs, such doses are comparable to classical radiotherapy treatment fractionation.

In the present study we have demonstrated that F98 glioma cells took up ultrasmall GdNPs without leading to a significant decrease in survival. Uptake of GdNPs was time dependent and reached a plateau after a $5 \mathrm{~h}$ of incubation with $2.1 \mathrm{mg} \mathrm{Gd} / \mathrm{mL}$. GdNPs increased the F98 cells' radiosensitivity primarily for keV photon energies with a larger effect than that observed with the same concentration of GdCA. Based on our data, we have concluded that radiosensitization of GdNPs could be attributed to two mechanisms. First, the photoelectric effect enhancement in the keV energy range, and second to biological interactions of GdNPs with the cells, resulting in proliferation arrest and the accumulation of cells at the G2/M interface of the cell cycle. In summary, our data provide strong support for the radiosensitizing effect of 
ultrasmall GdNPs over a broad energy range, even at high energies such as those used in conventional radiotherapy. Preliminary experiments have shown that the GdNPs are non-toxic when directly injected into the rats brains $(110 \mu \mathrm{g} \mathrm{Gd}$ in $5 \mu \mathrm{L}$ injected over $10 \mathrm{~min}$, unpublished data). Further in vivo pre-clinical studies on their circulation time and tumor uptake are warranted to further define the potential clinical benefit of ultrasmall GdNPs as radiation sensitizers. 


\section{Figure Legends}

Figure 1: Radiosensitizing effects of GdNPs and GdCA. All irradiations were performed with $51 \mathrm{keV}$ monochromatic X-rays.

A. F98 cells survival curves for control cells (०) and for cells incubated for $5 \mathrm{~h}$ with $2.1 \mathrm{mg} / \mathrm{mL}$ of GdNPs $(\Delta)$.

B. F98 survival curves for control cells $(\bullet)$ and cells irradiated in presence of $2.1 \mathrm{mg} / \mathrm{mL}$ $(\Delta), 5.0 \mathrm{mg} / \mathrm{mL}(\mathbf{\square})$ and $10.0 \mathrm{mg} / \mathrm{mL}(\boldsymbol{\nabla})$ of $\mathrm{GdCA}$.

Figure 2: $\alpha\left(G y^{-1}\right)$ and $\beta\left(G y^{-2}\right)$ parameters derived from the linear quadratic fits of survival curves for F98 cells treated with $2.1 \mathrm{mg} / \mathrm{mL}$ of $\operatorname{GdNPs}(\bullet)$ and $(\boldsymbol{\Delta})$, for $\alpha$ and $\beta$, respectively or $0,2.1,5.0$ and $10.0 \mathrm{mg} / \mathrm{mL}$ of $\operatorname{GdCA}(\circ)$ and $(\Delta)$, for $\alpha$ and $\beta$, respectively. The irradiations were performed with $51 \mathrm{keV}$ monochromatic X-rays. For GdCA, the plots of $\alpha$ and $\beta$ versus $\mathrm{Gd}$ concentration were both adjusted with a linear function (dotted lines, $R^{2}>0.95$ ).

Figure 3: Sensitization-enhancement ratios versus $\mathrm{X}$-ray dose. All irradiations were performed with $51 \mathrm{keV}$ monochromatic X-rays. F98 cells incubated for $5 \mathrm{~h}$ with $2.1 \mathrm{mg} / \mathrm{mL}$ of GdNPs $(\Delta)$. F98 cells irradiated in presence of $2.1 \mathrm{mg} / \mathrm{mL}(\boldsymbol{\Delta}), 5.0 \mathrm{mg} / \mathrm{mL}(\mathbf{\bullet})$ and $10.0 \mathrm{mg} / \mathrm{mL}(\diamond)$ of GdCA.

Figure 4: SER ${ }_{4 G y}$ of F98 cells irradiated at various X-ray energies with Gadolinium $(2.1 \mathrm{mg} / \mathrm{mL})$ Theoretical SER $\mathrm{SGy}_{4}(\mathbf{x})$ calculated for a homogeneous distribution of $\mathrm{Gd}$, compared to $\mathrm{SER}_{4 \mathrm{~Gy}}$ of F98 cells irradiated in presence of $\operatorname{GdCA}(\square)$ or in presence of $\operatorname{GdNPs}(\Delta)$.

Figure 5 : Uptake of GdNPs by F98 cells as a function of the incubation time $(t)$ assessed by ICP-MS. Data were adjusted by $\alpha . t^{\beta}$, with $\alpha=0.37 \pm 0.03, \beta=0.34 \pm 0.05$ and $X^{2}=1.1$.

Figure 6: Distribution of F98 cells in the different phases of the cell cycle (G1, S and G2/M) for control cells (dark grey) and cells incubated for $5 \mathrm{~h}$ at $37^{\circ} \mathrm{C}$ with $2.1 \mathrm{mg} / \mathrm{mL}$ GdNPs (light grey). a) Cell cycle distribution immediately after $5 \mathrm{~h}$ incubation. b) Cell cycle distribution at $24 \mathrm{~h}$ after the end of the incubation period. 
Figure 1:
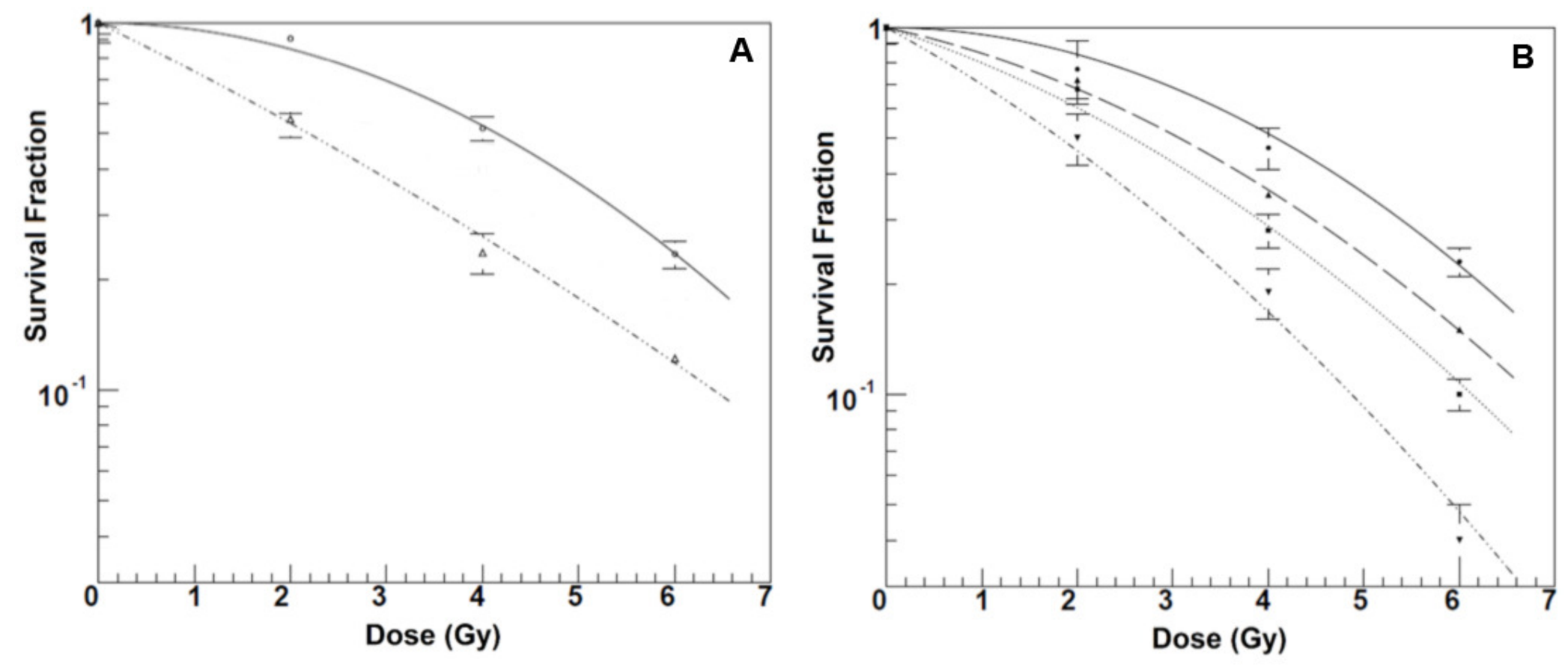
Figure 2 :

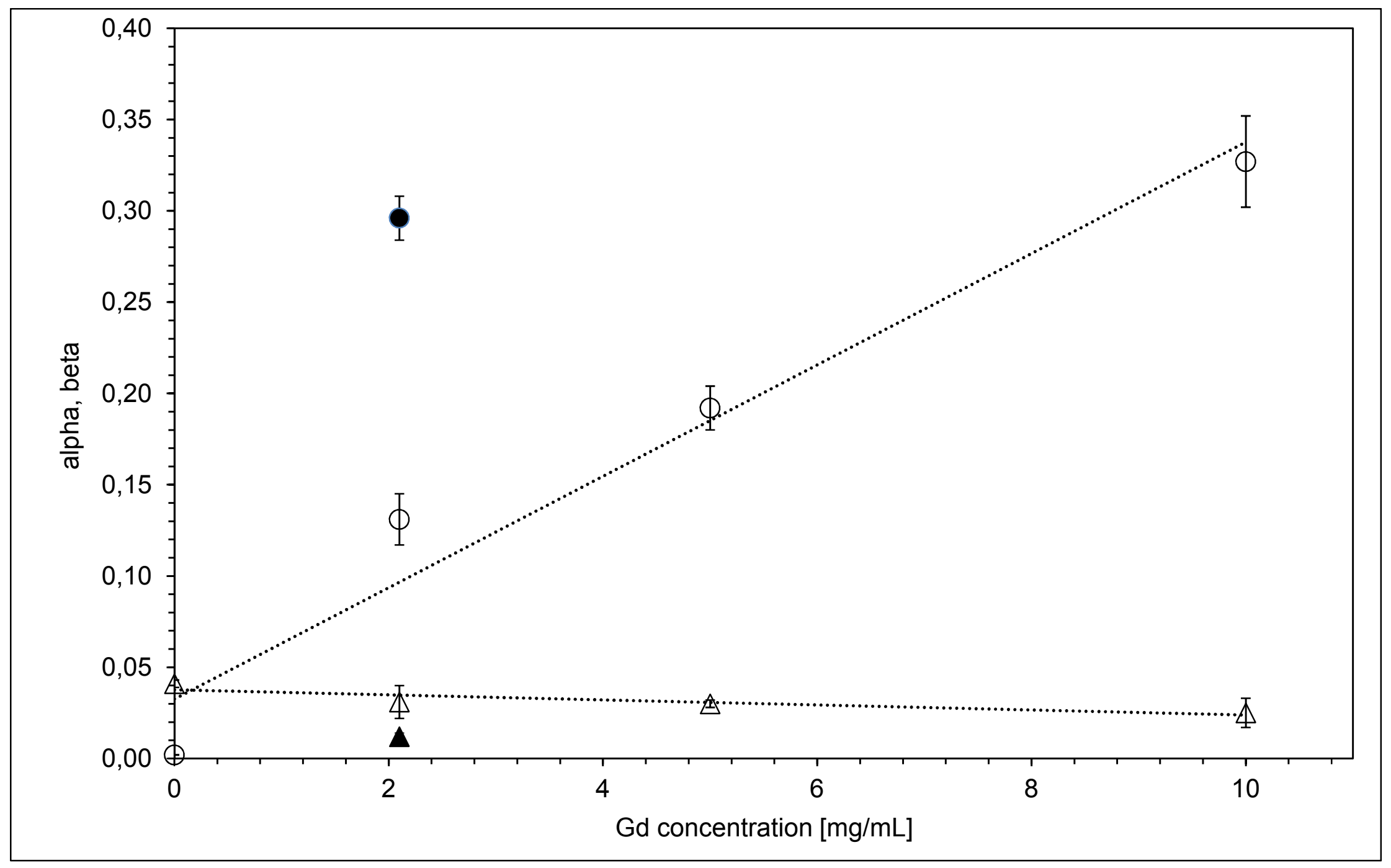




\section{Figure 3 :}

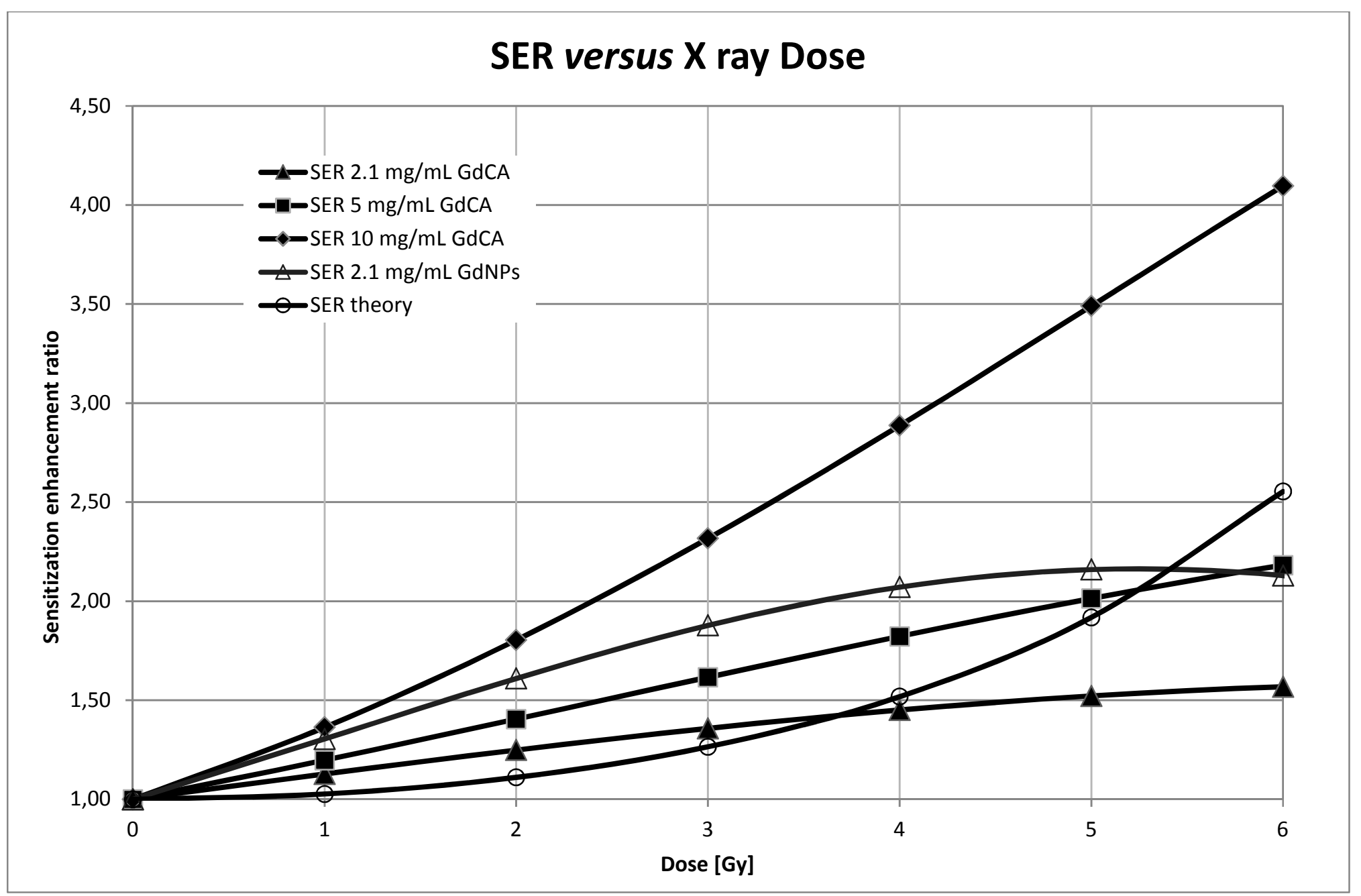


Figure 4:

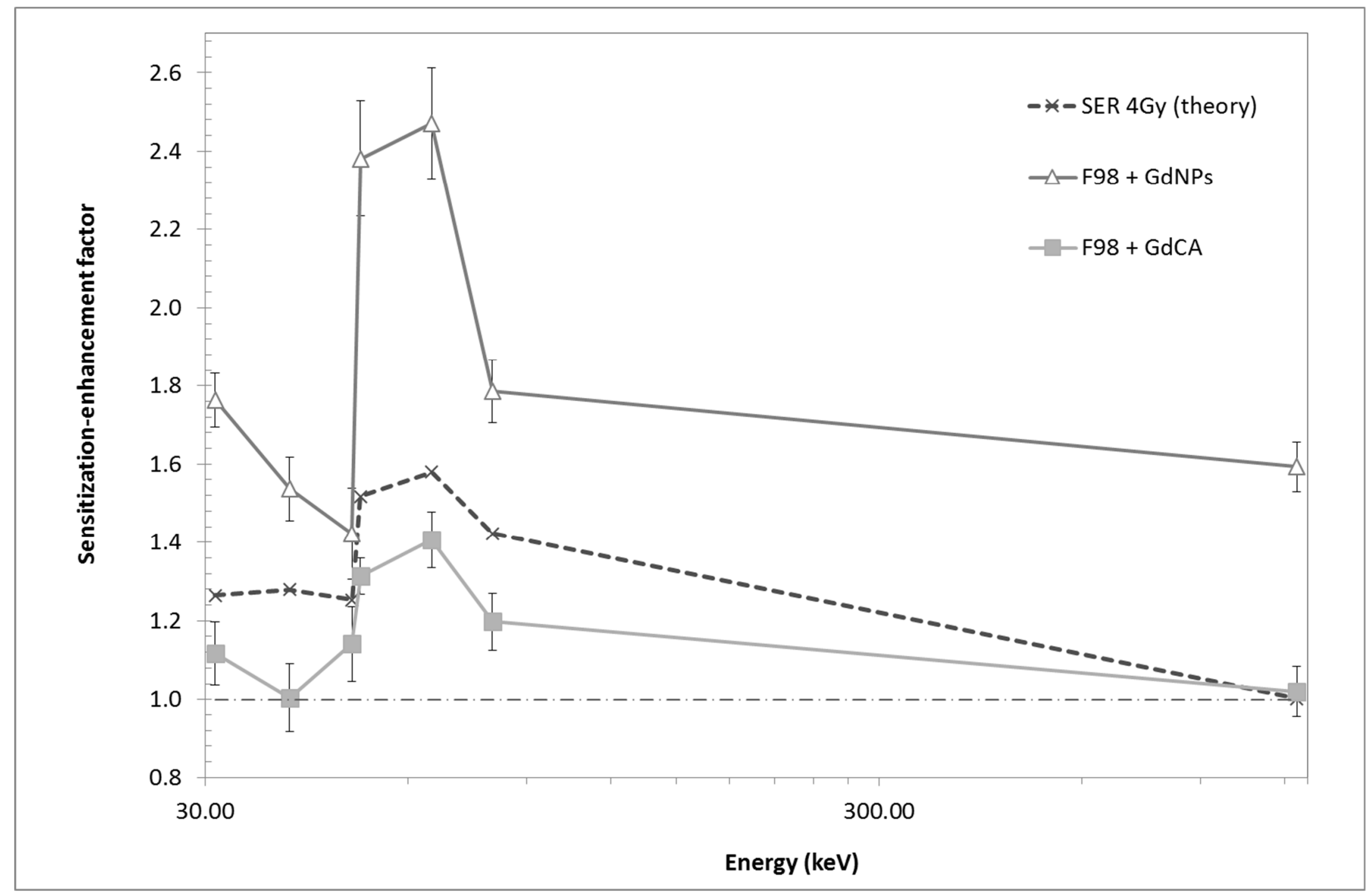


Figure 5:

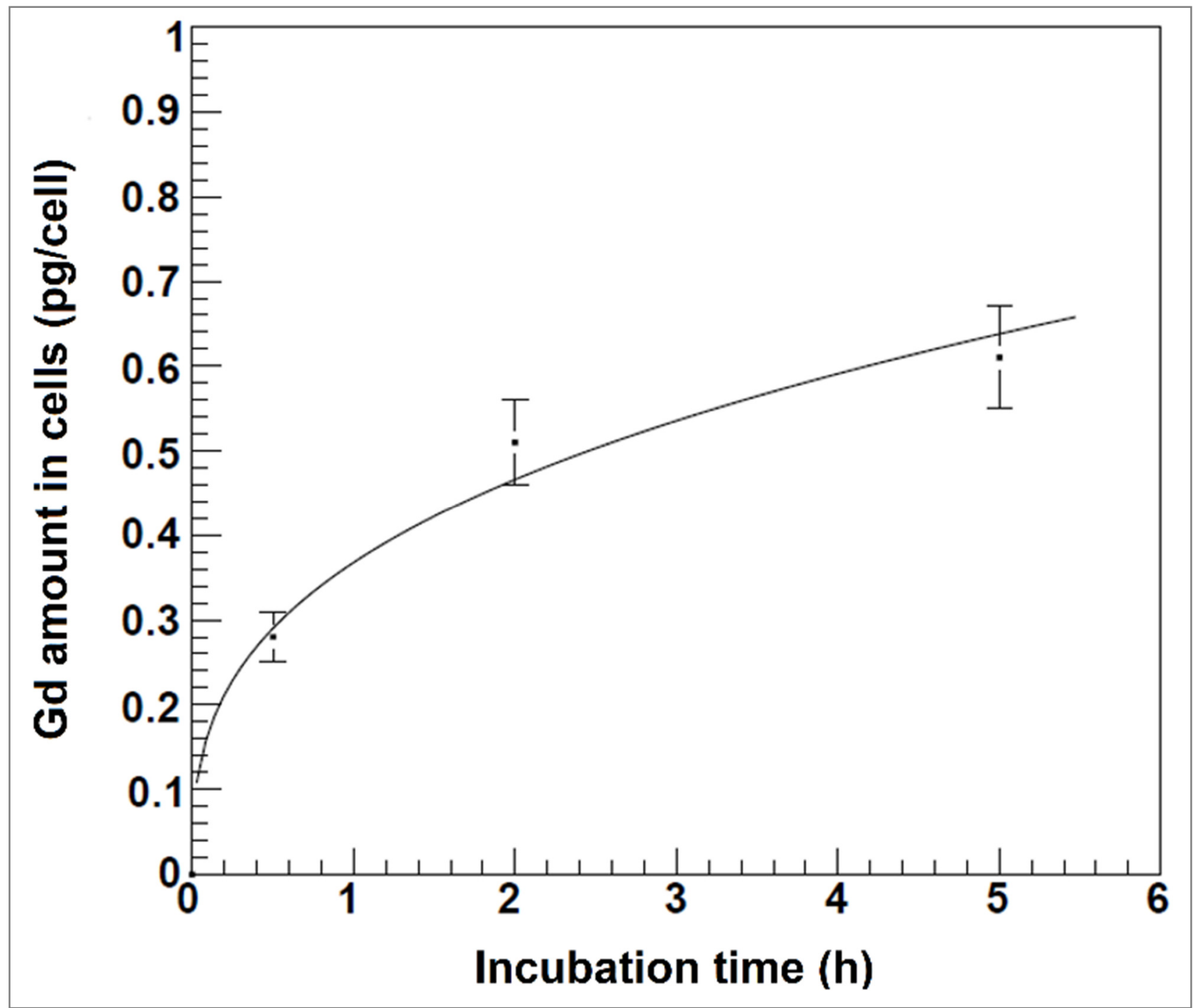


Figure 6:
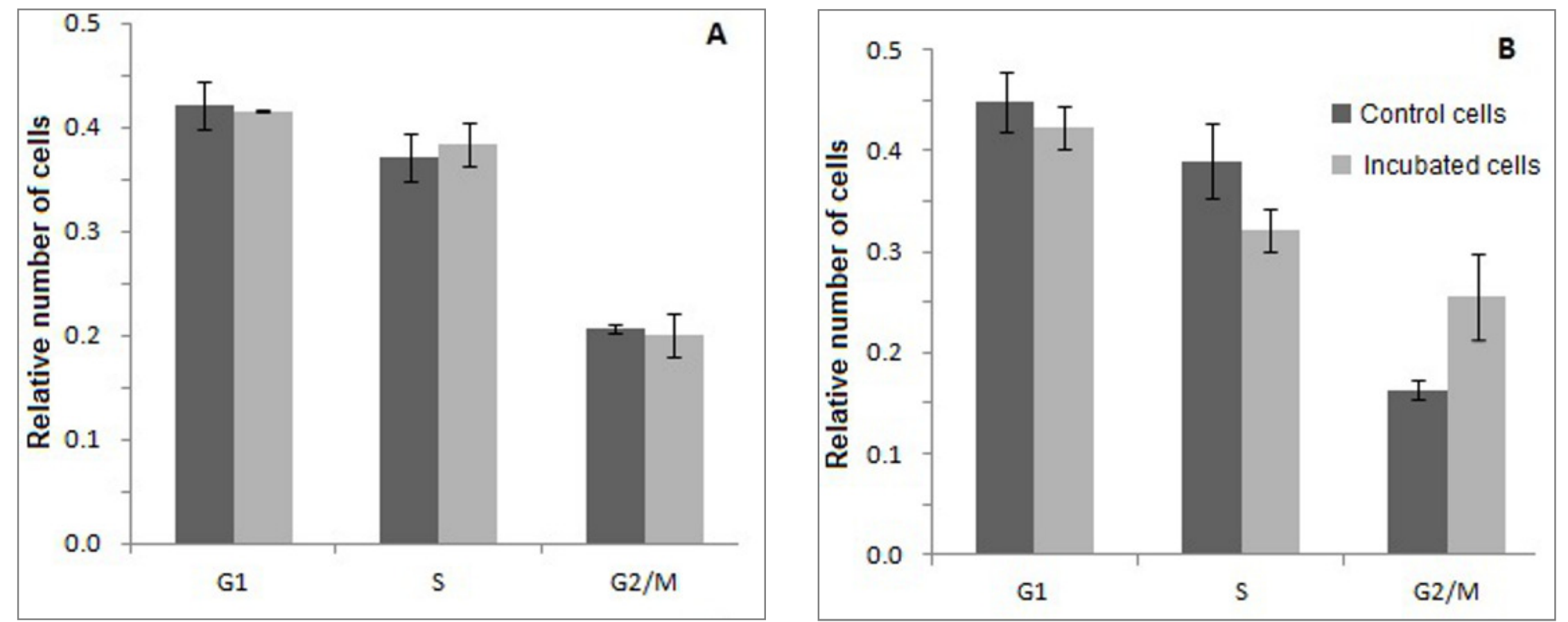


\section{REFERENCES}

1. Stupp, R., et al., Radiotherapy plus concomitant and adjuvant temozolomide for glioblastoma. The New England journal of medicine, 2005. 352: p. 987-96.

2. Stupp, R., et al., Effects of radiotherapy with concomitant and adjuvant temozolomide versus radiotherapy alone on survival in glioblastoma in a randomised phase III study: 5-year analysis of the EORTC-NCIC trial. The lancet oncology, 2009. 10: p. 459-66.

3. Hainfeld, J.F., et al., Gold nanoparticles enhance the radiation therapy of a murine squamous cell carcinoma. Physics in medicine and biology, 2010. 55: p. 3045-59.

4. Hainfeld, J.F., et al., Gold nanoparticle imaging and radiotherapy of brain tumors in mice. Nanomedicine (London, England), 2012.

5. Norman, A., K.S. Iwamoto, and S.T. Cochran, Iodinated contrast agents for brain tumor localization and radiation dose enhancement. Investigative radiology, 1991. 26 Suppl 1: p. S120-1; discussion S125-8.

6. Boudou, C., et al., Monte Carlo dosimetry for synchrotron stereotactic radiotherapy of brain tumours. Physics in medicine and biology, 2005. 50: p. 4841-51.

7. Mesa, A.V., et al., Dose distributions using kilovoltage $x$-rays and dose enhancement from iodine contrast agents. Phys Med Biol, 1999. 44(8): p. 1955-68.

8. $\quad$ Pignol, J.P., et al., Clinical significance of atomic inner shell ionization (ISI) and Auger cascade for radiosensitization using IUdR, BUdR, platinum salts, or gadolinium porphyrin compounds. Int J Radiat Oncol Biol Phys, 2003. 55(4): p. 1082-91.

9. De Stasio, G., et al., Gadolinium in human glioblastoma cells for gadolinium neutron capture therapy. Cancer Res, 2001. 61(10): p. 4272-7.

10. Karnas, S.J., et al., Monte Carlo simulations and measurement of DNA damage from xray-triggered auger cascades in iododeoxyuridine (IUdR). Radiat Environ Biophys, 2001. 40(3): p. 199-206.

11. Terrissol, M., S. Edel, and E. Pomplun, Computer evaluation of direct and indirect damage induced by free and DNA-bound iodine-125 in the chromatin fibre. Int J Radiat Biol, 2004. 80(11-12): p. 905-8.

12. Ceberg, C., et al., Photon activation therapy of $R G 2$ glioma carrying Fischer rats using stable thallium and monochromatic synchrotron radiation. Phys Med Biol. 57(24): p. 8377-91.

13. Solberg, T.D., K.S. Iwamoto, and A. Norman, Calculation of radiation dose enhancement factors for dose enhancement therapy of brain tumours. Phys Med Biol, 1992. 37(2): p. 439-43.

14. Robar, J.L., S.A. Riccio, and M.A. Martin, Tumour dose enhancement using modified megavoltage photon beams and contrast media. Phys Med Biol, 2002. 47(14): p. 243349.

15. Gastaldo, J., et al., Normoxic polyacrylamide gel doped with iodine: response versus $X$ ray energy. Eur J Radiol, 2008. 68(3 Suppl): p. S118-20.

16. Corde, S., et al., Sensitivity variation of doped Fricke gel irradiated with monochromatic synchrotron X rays between 33.5 and $80 \mathrm{keV}$. Radiat Prot Dosimetry, 2005. 117(4): p. 425-31.

17. Tsiamas, P., et al., Impact of beam quality on megavoltage radiotherapy treatment techniques utilizing gold nanoparticles for dose enhancement. Phys Med Biol. 58(3): p. 451-64.

18. McMahon, S.J., et al., Radiotherapy in the presence of contrast agents: a general figure of merit and its application to gold nanoparticles. Phys Med Biol, 2008. 53(20): p. 5635-51.

19. Coulter, J.A., et al., Cell type-dependent uptake, localization, and cytotoxicity of $1.9 \mathrm{~nm}$ gold nanoparticles. International Journal of Nanomedicine, 2012. 7: p. 2673-2685. 
20. Jain, S., et al., Cell-Specific Radiosensitization by Gold Nanoparticles at Megavoltage Radiation Energies. International Journal of Radiation Oncology Biology Physics, 2011. 79(2): p. 531-539.

21. Lechtman, E., et al., A Monte Carlo-based model of gold nanoparticle radiosensitization accounting for increased radiobiological effectiveness. Phys Med Biol. 58(10): p. 3075-87.

22. Butterworth, K.T., et al., Evaluation of cytotoxicity and radiation enhancement using $1.9 \mathrm{~nm}$ gold particles: potential application for cancer therapy. Nanotechnology, 2010. 21(29).

23. Butterworth, K.T., et al., Physical basis and biological mechanisms of gold nanoparticle radiosensitization. Nanoscale, 2012. 4(16): p. 4830-4838.

24. McMahon, S.J., et al., Nanodosimetric effects of gold nanoparticles in megavoltage radiation therapy. Radiother Oncol. 100(3): p. 412-6.

25. McMahon, S.J., K.M. Prise, and F.J. Currell, Comment on 'Implications on clinical scenario of gold nanoparticle radiosensitization in regards to photon energy, nanoparticle size, concentration and location'. Physics in Medicine and Biology, 2012. 57(1): p. 287-290.

26. Mowat, P., et al., Glioma cells radiosensitization with lanthanid-based nanoparticles. Bulletin Du Cancer, 2011. 98: p. S69-S70.

27. Mowat, P., et al., In Vitro Radiosensitizing Effects of Ultrasmall Gadolinium Based Particles on Tumour Cells. Journal of Nanoscience and Nanotechnology, 2011. 11(9): p. 7833-7839.

28. Le Duc, G., et al., Toward an image-guided microbeam radiation therapy using gadolinium-based nanoparticles. Acs Nano. 5(12): p. 9566-74.

29. Roeske, J.C., et al., Characterization of the theorectical radiation dose enhancement from nanoparticles. Technol Cancer Res Treat, 2007. 6(5): p. 395-401.

30. Boudou, C., et al., Monte Carlo dosimetry for synchrotron stereotactic radiotherapy of brain tumours. Phys Med Biol, 2005. 50(20): p. 4841-51.

31. Boudou, C., et al., Polymer gel dosimetry for synchrotron stereotactic radiotherapy and iodine dose-enhancement measurements. Phys Med Biol, 2007. 52(16): p. 4881-92.

32. Karnas, S.J., et al., Optimal photon energies for IUdR K-edge radiosensitization with filtered $x$-ray and radioisotope sources. Phys Med Biol, 1999. 44(10): p. 2537-49.

33. Mesbahi, A., F. Jamali, and N. Garehaghaji, Effect of photon beam energy, gold nanoparticle size and concentration on the dose enhancement in radiation therapy. Bioimpacts. 3(1): p. 29-35.

34. Robar, J.L., Generation and modelling of megavoltage photon beams for contrastenhanced radiation therapy. Phys Med Biol, 2006. 51(21): p. 5487-504.

35. Lux, F., et al., Ultrasmall rigid particles as multimodal probes for medical applications. Angew Chem Int Ed Engl. 50(51): p. 12299-303.

36. Franken, N.A. and G.W. Barendsen, Enhancement of radiation effectiveness by hyperthermia and incorporation of halogenated pyrimidines at low radiation doses as compared with high doses: implications for mechanisms. Int J Radiat Biol, 2014. 90(4): p. 313-7.

37. Miladi, I., et al., Combining ultrasmall gadolinium-based nanoparticles with photon irradiation overcomes radioresistance of head and neck squamous cell carcinoma. Nanomedicine, 2015. 11(1): p. 247-57. 